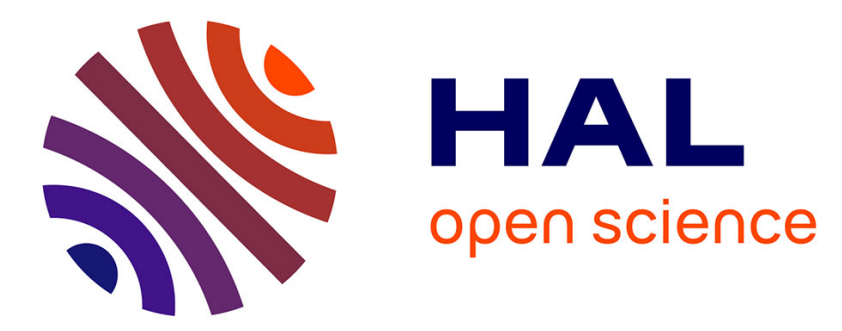

\title{
Approximations of the macroscopic strength criterion of reinforced soils, with application to structural stability analyses
}

Maxime Gueguin, Ghazi Hassen, Patrick de Buhan

\section{- To cite this version:}

Maxime Gueguin, Ghazi Hassen, Patrick de Buhan. Approximations of the macroscopic strength criterion of reinforced soils, with application to structural stability analyses. 14th International Conference of the International Association for Computer Methods and Advances in Geomechanics, Sep 2014, Kyoto, Japan. pp.1139-1144. hal-01071389

HAL Id: hal-01071389

https://hal-enpc.archives-ouvertes.fr/hal-01071389

Submitted on 4 Oct 2014

HAL is a multi-disciplinary open access archive for the deposit and dissemination of scientific research documents, whether they are published or not. The documents may come from teaching and research institutions in France or abroad, or from public or private research centers.
L'archive ouverte pluridisciplinaire HAL, est destinée au dépôt et à la diffusion de documents scientifiques de niveau recherche, publiés ou non, émanant des établissements d'enseignement et de recherche français ou étrangers, des laboratoires publics ou privés. 


\title{
Approximations of the macroscopic strength criterion of reinforced soils, with application to structural stability analyses
}

\author{
M. Gueguin, G. Hassen \& P. de Buhan \\ Laboratoire Navier (UMR 8205), CNRS, ENPC, IFSTTAR \\ Université Paris-Est, Marne-La-Vallée, France.
}

\begin{abstract}
The macroscopic strength properties of a stone column reinforced soil are investigated numerically. Using the kinematic approach of the yield design theory applied to the reinforced soil's unit cell, a numerical upper bound estimate of its strength domain is provided. Since this domain cannot be used directly for a structural stability analysis, an approximation method is performed, using a sum of ellipsoidal sets. The result is a rigorous upper bound estimate for the macroscopic strength criterion depending on few parameters. The relative error of this method is quantified not exceeding a few percents. Then, this approximation is used in order to treat the problem of an embankment resting upon a stone column reinforced soil. Again, performing the kinematic approach on this structure, a rigorous upper bound estimate of the ultimate stability factor is obtained numerically. The gain in terms of ultimate capacity improvement is observed, as compared to the non reinforced configuration. This result is compared to a simplified analysis, based on a rule of mixture formula, where strong disparities are highlighted.
\end{abstract}

\section{INTRODUCTION}

\subsection{Technological context}

There are many ways to improve the poor quality of soils, in order to provide enhanced bearing capacity to the native soil. In the case of purely cohesive soft clayey soils, the techniques consist in incorporating an additional material with improved strength properties. Traditionally, the reinforcement techniques use a periodic distribution of columns, which can be obtained by mixing the weak soil mass with a percentage of lime or lime-cement, like in the so-called lime column technique (Broms 1982), or by replacing a percentage of the native soil by a vibrocompacted granular material or ballast, known as stone column reinforcement technique (Priebe 1995).

This contribution is focused on the stability analysis of an embankment resting upon a stone column reinforced soil (see Fig.1). The complexity of the direct analysis of such a three-dimensional problem, analytically or numerically, has already been highlighted by some authors (Jellali et al. 2007, Hassen et al. 2013). One rigorous alternative way to do so is to use the periodic homogenization method in the context of the yield design theory.

\subsection{Yield design homogenization method}

The well-known homogenization approach has been applied to the yield design theory in a general framework (Suquet 1987) or in the context of reinforced soil mechanics (de Buhan 1986) about thirty years ago. For periodic media, it first consists in exhibiting from the initial problem the smallest representative volume of reinforced soil, called unit cell.

Then, a yield design auxiliary problem, is solved on this unit cell, considered here as a (micro)structure (see Fig.1). The result of this first calculation is an evaluation of the anisotropic macroscopic strength domain of the reinforced soil, denoted here by $\mathbf{G}^{\text {hom }}$. The determination of the macroscopic strength domain of a stone column reinforced soil is presented in Section 2.

The final step of the homogenization method is to solve the homogenized equivalent problem. The volume occupied by the reinforced soil in the initial problem is now replaced by an equivalent homogenized material, which obey the so-obtained macroscopic strength criterion. Section 3 is devoted to solving the homogenized problem.

The interesting result of the yield design homogenization approach is that the homogenized configuration leads to the same ultime load as the initial problem, provided that the characteristic length of the unit cell (denoted here by $L$ ) is kept way smaller than the 


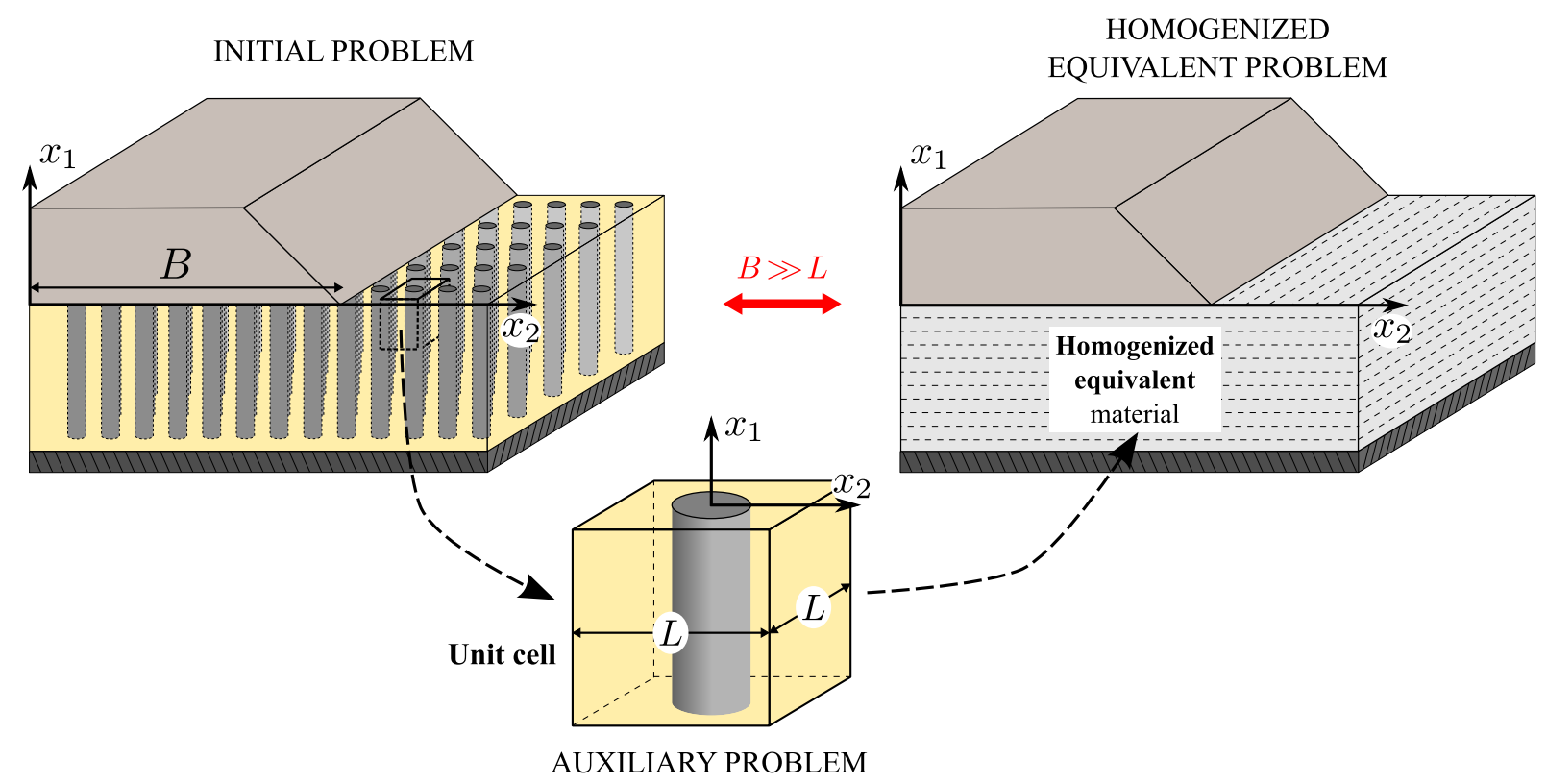

Figure 1: Principle of the periodic homogenization method.

characteristic dimension of the structural problem, denoted by $B$.

\section{EVALUATION OF THE MACROSCOPIC STRENGTH DOMAIN}

\subsection{Solving the yield design auxiliary problem}

The native soil obeys a Tresca strength criterion of the form:

$f^{s}(\underline{\underline{\sigma}})=\sigma_{M}-\sigma_{m}-2 C_{s} \leq 0$

where $\sigma_{M}$ and $\sigma_{m}$ are the major and minor principal stress components respectively and $C_{s}$ denotes the cohesion of the soft clay.

The stone columns are incorporated into the native soil with a volume fraction $\eta$. The strength condition of their purely frictional constituent material is described by a Mohr-Coulomb condition, defined by the following yield strength function:

$f^{r}(\underline{\underline{\sigma}})=\left(1+\sin \varphi_{r}\right) \sigma_{M}-\left(1-\sin \varphi_{r}\right) \sigma_{m} \leq 0$

with $\varphi_{r}$ representing the friction angle of the reinforcing material.

The resolution of the yield design auxiliary problem implies to find a stress field $\underline{\underline{\sigma}}$ in equilibrium (statically admissible) with the macroscopic stress loading

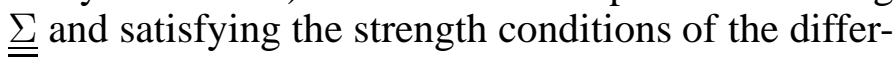
$\overline{\overline{\text { ent }}}$ constituents at any point of the unit cell:

$\underline{\underline{\Sigma}} \in \mathbf{G}^{\text {hom }} \Leftrightarrow\left\{\begin{array}{l}\exists \underline{\underline{\underline{\sigma}}} \text { statically admis. with } \underline{\underline{\underline{\Sigma}}}(\underline{\underline{\sigma}}) \leq 0 \text { in the soil } \\ f^{r}(\underline{\underline{\underline{\sigma}}}) \leq 0 \text { in the columns }\end{array}\right.$

As for a Tresca or Mohr-Coulomb criterion, the macroscopic strength domain $\mathbf{G}^{\text {hom }}$ may be defined by either a yield strength function or a support function, denoted here by $\pi^{\text {hom }}$ and obtained by dualisation of the strength condition. This second definition involves the macroscopic strain rate tensor $\underline{\underline{D}}$, associated with $\underline{\underline{\Sigma}}$, and is given by:

$$
\mathbf{G}^{h o m}\left(\eta, C_{s}, \varphi_{r}\right)=\bigcap_{\underline{\underline{D}}}\left\{\underline{\underline{\underline{\Sigma}}} \mid \underline{\underline{\Sigma}}: \underline{\underline{D}} \leq \pi^{h o m}(\underline{\underline{D}})\right\}
$$

In the case of stone column reinforced soils, the macroscopic strength domain is a convex set depending on the reinforcement volume fraction as well as the strength properties of both constituents.

The exact resolution of the yield design auxiliary problem being impossible in most cases, approaches have been developed to frame $\mathbf{G}^{\text {hom }}$. The static approach of the yield design theory, based on a stress field statically admissible with $\Sigma$, permits to obtain a lower bound, whereas the kinematic approach, which consists in considering a velocity field admissible with $\underline{D}$, gives an upper bound. Only the second approach will be used here and we will obtain as a result a strength domain $\mathbf{G}^{\text {kine }}$, including $\mathbf{G}^{\text {hom }}$ :

$\mathbf{G}^{\text {hom }} \subseteq \mathbf{G}^{\text {kine }}$

In order to obtain accurate bounds, the static and kinematic approaches of the yield design theory, which are expressed as optimization problems, can be solved using numerical methods. It provides quite good assessment of the macroscopic strength domain (Gueguin et al. 2014a).

The problem of the embankment resting upon a reinforced soil may be considered as a plane strain problem in the $\left(x_{1}, x_{2}\right)$-plane, where $x_{1}$ denotes the reinforcement direction (see Fig.1). The numerical determination of $\mathbf{G}^{\mathrm{kine}}$ under these conditions is then de- 
rived for a stone column reinforced soil, with the following characteristics:

$\eta=0.2$ and $\varphi_{r}=40^{\circ}$

Figure 2 depicts the so-obtained upper bound in the space of non dimensional stresses $\left(\Sigma_{11} / C_{s}, \Sigma_{22} / C_{s}, \Sigma_{12} / C_{s}\right)$. Some important remarks should be made at this stage. First, there are many strain rate directions which don't admit any load limit, so that the support function value becomes infinite. It is also worth noting that for a pure shear stress sollicitation, the strength of the reinforced soil cannot exceed the cohesion of the native soil $C_{s}$. Moreover, despite the fact that the reinforcement material is cohesionless, the reinforced soil displays a significant strength in the region of tensile stresses, due to the fact that the column is surrounded by the native cohesive soil.

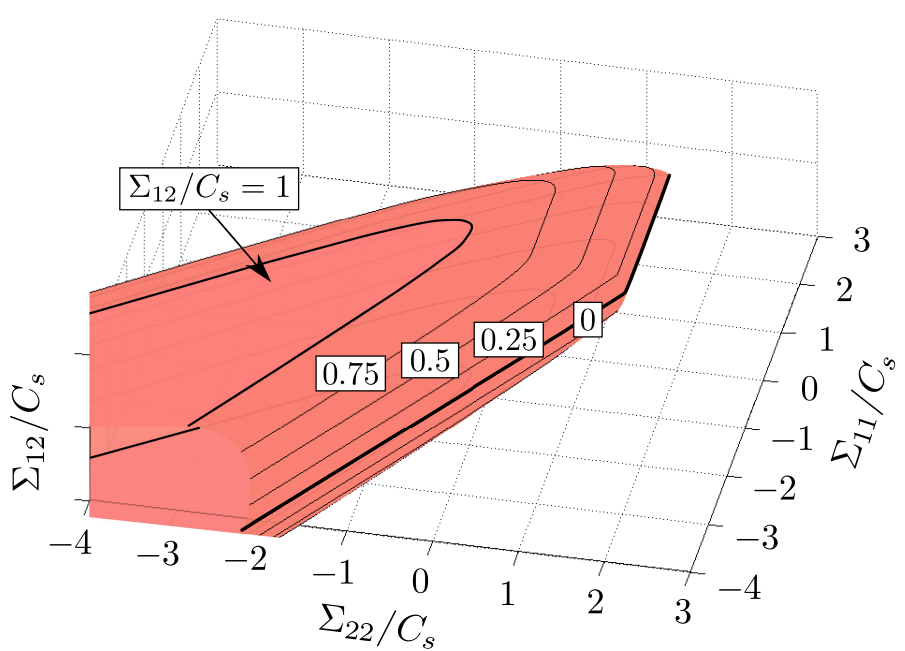

Figure 2: Upper bound to the macroscopic strength domain of a stone column reinforced soil.

\subsection{Approximation of the macroscopic strength criterion}

The so-obtained macroscopic strength criterion can hardly be incorporated into the homogenized equivalent problem, since the complex corresponding yield surface cannot be expressed through analytical formulas such as (1) and (2). In the context of bounded strength domains, some authors have developed a numerical procedure, based on the use of convex ellipsoidal sets, which permits to approximate these domains (Bleyer and de Buhan 2013).

An extension of this method has been proposed in order to take unbounded strength domains into account (Gueguin et al. 2013). It provides accurate closed-form approximations to the macroscopic criteria, involving relatively few parameters, which makes the approximated criteria much easier to handle than the initial ones.
This method is applied here to approximate the obtained upper bound of $\mathbf{G}^{\text {hom }}$. In order to keep a rigorous status for the strength domain $\mathbf{G}_{\text {app }}^{\text {kine }}$, which will used for an upcoming structural application, this approximation is chosen as an upper bound of $\mathbf{G}^{\text {kine }}$. Thus, it is ensured that:

$\mathbf{G}^{\text {hom }} \subseteq \mathbf{G}^{\text {kine }} \subseteq \mathbf{G}_{\text {app }}^{\text {kine }}$

The approximation is performed here with a sum of 5 ellipsoidal sets. A cross section of the yield surfaces of the upper bound estimate and its approximation is diplayed in Figure 3, with $\Sigma_{12} / C_{s}=0$. It confirms the accuracy of the approximation method, since for some macroscopic strain rate directions the two strength domains are coincident.

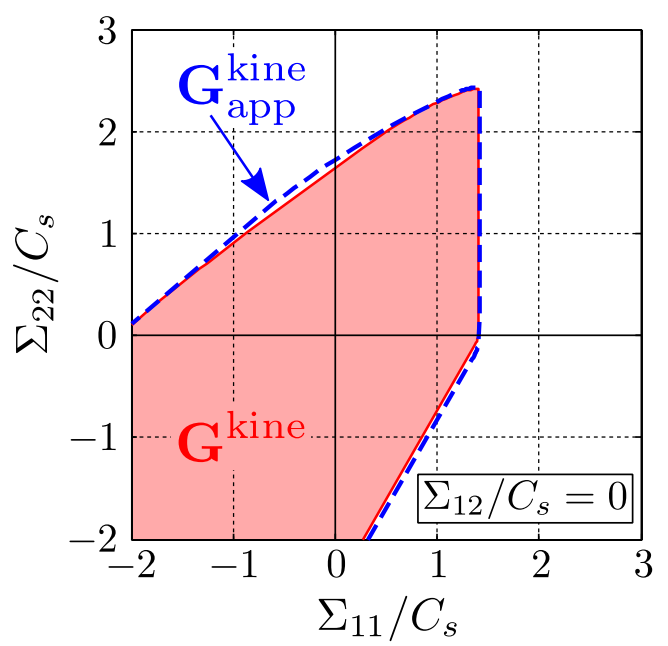

Figure 3: Cross section of the numerical and approximated upper bound estimates of the macroscopic strength domain of a stone column reinforced soil.

\subsection{Remarks on the relative gap}

The relative error due to the approximation method can be quantified for each macroscopic strain rate admitting a limit load. The macroscopic strain rate tensor $\underline{D}$ can be defined by two angles in the space $\left(D_{11}, \overline{D_{22}}, 2 D_{12}\right)$. The angle $\gamma$ corresponds to the orientation of $\underline{D}$ in the $\left(D_{11}, D_{22}\right)$-plane and $\delta$ indicates the value of the shear strain component (see Fig.4). If the strength domain is a bounded set, the couple orientations belongs to the whole space: $(\gamma, \delta) \in([-\pi, \pi],[-\pi / 2, \pi / 2])$.

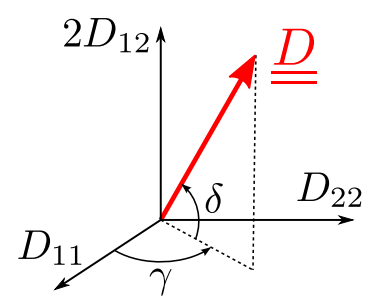

Figure 4: Angular parametrization of the plane strain loading.

For a given couple $(\gamma, \delta)$, the error is then defined as the relative gap between the support function of the 
approximated criterion $\mathbf{G}_{\text {app }}^{\text {kine }}$ and that of the numerical upper bound estimate $\mathbf{G}^{\text {kine }}$ :

$\operatorname{relgap}\left(\mathbf{G}_{\text {app }}^{\text {kine }}, \mathbf{G}^{\text {kine }}\right)=\frac{\pi_{\text {app }}^{\text {kine }}(\gamma, \delta)-\pi^{\text {kine }}(\gamma, \delta)}{\pi^{\text {kine }}(\gamma, \delta)}$

Figure 5 displays the value of this relative gap as a function of the strain rate orientation $(\gamma, \delta)$. The maximum value of this relative error is $10.55 \%$ for the approximation by a sum of 5 ellipsoids, which the average value on all the strain rate directions admitting a limit load, is equal to $1.87 \%$. It confirms the quality of the so-obtained approximated domain, which could be used now to treat a structural problem with confidence.

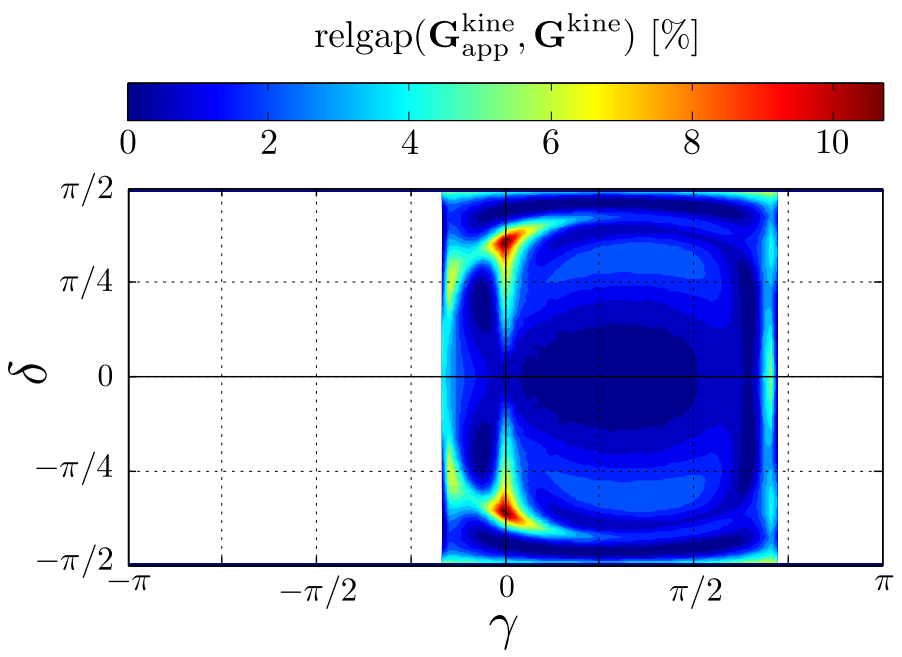

Figure 5: Relative gap depending on the strain rate orientation $(\gamma, \delta)$

\section{APPLICATION TO A STABILITY ANALYSIS PROBLEM}

\subsection{Problem statement}

As an application of the yield design homogenization approach, we consider now an embankment resting upon a reinforced soil (see Fig.6). The total length of the stone column reinforced zone is denoted by $B_{0}$ and its depth by $h$. The overlying slope is made of a purely frictional material (friction angle $\phi$ ). Its geomety depends on the height $H$, the length $B$ and the slope angle $\Theta$. The unique loading parameter of the problem is the specific weight $\Gamma$ of the embankment constituent soil, which, for the sake of simplicity, will be taken equal to that of the underlying soft clay and column material.

As it has been explained previously, this problem may be investigated under plane strain conditions. The stability of the embankment is governed by the non dimensional parameter $\Gamma H / C_{s}$, called stability factor. The stability of the structure is ensured as far as this factor remains lower than a critical value, denoted by $F^{+}$, depending on the following geometrical and strength parameters:

$$
\frac{\Gamma H}{C_{s}} \leq F^{+}\left(\phi, \eta, \varphi_{r} ; \Theta, H / h\right)
$$

the horizontal lengths $B$ and $B_{0}$ being kept fixed.

This problem has already been studied analytically in the case of a purely cohesive reinforcement material (Jellali et al. 2011). Here, due to the high frictional strength properties of the columns, the problem must be treated numerically. Therefore, the whole structure is discretized into six-noded triangular elements, as shown in Figure 6.

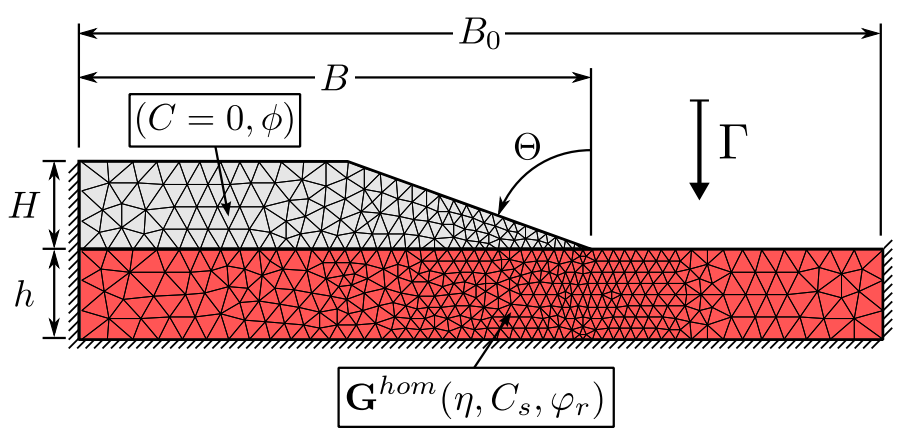

Figure 6: Adopted finite element mesh for an upper bound estimate of the ultimate stability factor, using ellipsoidal set approximation of the macroscopic strength criterion.

In order to obtain an upper bound estimate of the ultimate stability factor, a kinematic approach is performed using numerical optimization of the velocity field (Makrodimopoulos and Martin 2007). As a result, the upper bound estimate $F^{\mathrm{ub}}$, as well as the associated velocity field $\underline{U}^{\text {opt }}$, are obtained. The numerical implementation ensures that:

$F^{+}\left(\phi, \eta, \varphi_{r} ; \Theta, H / h\right) \leq F^{\mathrm{ub}}\left(\mathbf{G}^{h o m}, \underline{U}^{\mathrm{opt}}\right)$

\subsection{Results for a stone column reinforced soil}

Since the exact macroscopic strength domain $\mathbf{G}^{\text {hom }}$ is unknown and its upper bound estimate $\mathbf{G}^{\text {kine }}$ cannot be expressed as an analytical function, we consider that the anisotropic strength criterion of the homogenized equivalent material corresponds to the ellipsoidal set approximation $\mathbf{G}_{\mathrm{app}}^{\mathrm{kine}}$, introduced in the previous section.

As an illustrative example, the following geometrical characteristics have been selected:

$H=h=10 \mathrm{~m}, B_{0}=90 \mathrm{~m}, B=57 \mathrm{~m}, \Theta=70^{\circ}$

The reinforcement volume fraction and the friction angle of the columns are the same as in the previous section and the friction angle of the embankement $\phi$ may be taken as smaller than $\varphi_{r}$, since it has not been vibrocompacted.

$\phi=30^{\circ}, \eta=0.2$ and $\varphi_{r}=40^{\circ}$ 
First the optimization is carried out for a non reinforced soil. The underlying soil layer is taken as a purely cohesive material with the cohesion of the native soil $C_{s}$. The corresponding upper bound estimate of $F^{+}$is:

$$
F^{\mathrm{ub}}\left(\mathbf{G}^{\mathrm{nr}}, \underline{U}_{\mathrm{nr}}^{\mathrm{opt}}\right)=6.48
$$

and the associated velocity field (failure mechanism) is displayed in Figure 7(a).

The same calculation is performed for a stone column reinforced soil. After optimization, the ultimate stability factor is smaller than:

$F^{\mathrm{ub}}\left(\mathbf{G}_{\text {app }}^{\mathrm{kine}}, \underline{U}_{\mathrm{app}}^{\mathrm{opt}}\right)=15.29$

The comparison of the upper bounds (13) and (14) suggests that the reinforcement of the soil layer improves the stability of the embankment by a factor 2.36 . The velocity field $\underline{U}_{\mathrm{app}}^{\mathrm{opt}}$, associated with this upper bound estimate, is represented in Figure 7(b). We can note that the failure mechanism in the reinforced case is more superficial than for the non reinforced soil. This has been also highlighted for a purely cohesive reinforcement material (Jellali et al. 2011).

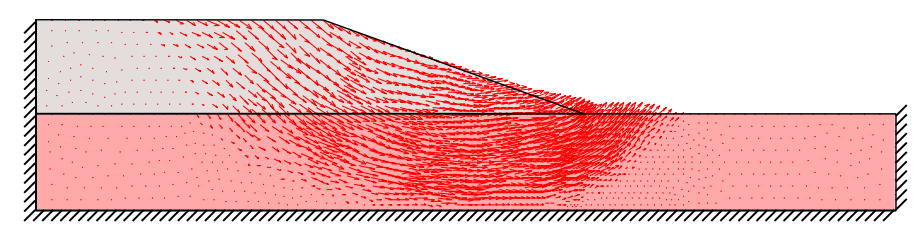

(a) Non reinforced soil

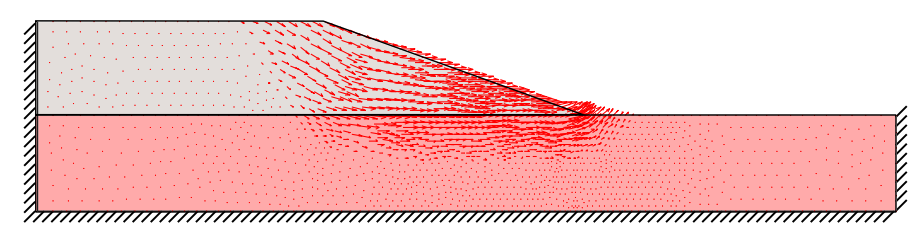

(b) Stone column reinforced soil

Figure 7: Failure mechanism obtained by a numerical optimization.

It is then possible to evaluate the relative error made on the stability factor estimate, due to the approximation method. Since the velocity field $\underline{U}_{\text {app }}^{\text {opt }}$ has been obtained numerically, we can use the kinematic approach of the macroscopic strength domain $\mathbf{G}^{\text {kine }}$ to evaluate an upper bound estimate of $F^{+}$.

$\frac{F^{\mathrm{ub}}\left(\mathbf{G}_{\mathrm{app}}^{\mathrm{kine}}, \underline{U}_{\mathrm{app}}^{\mathrm{opt}}\right)-F^{\mathrm{ub}}\left(\mathbf{G}^{\mathrm{kine}}, \underline{U}_{\mathrm{app}}^{\mathrm{opt}}\right)}{F^{\mathrm{ub}}\left(\mathbf{G}^{\mathrm{kine}}, \underline{U}_{\mathrm{app}}^{\mathrm{opt}}\right)}=4.52 \%$

The global error only amounts to a few percents. It confirms that using an ellipsoid set approximation allows to treat stability problems, unlike the initial upper bound estimate, and provides an accurate result with a rigorous status of upper bound.

\subsection{Comparison with an approach based on a simplified criterion}

A common design practice consists in considering the stone column reinforced soil as a Mohr-Coulomb material, the strength characteristics of which are equal to the weighted average values of the strength properties of the soil and column material (Priebe 1995).

In its simplest form, this average value is calculated according to a rule of mixture formula involving the reinforcement volume fraction:

$\langle C\rangle=\eta C_{r}+(1-\eta) C_{s}$

$\tan \langle\varphi\rangle=\eta \tan \varphi_{r}+(1-\eta) \tan \varphi_{s}$

where $C_{r}$ and $\varphi_{s}$ are null in the case of soft clays reinforced by stone columns.

Using the same finite element mesh and geometrical characteristics as for the previous stability analysis, we obtain an upper bound estimate of $F^{+}$with this simplified criterion equal to

$$
F^{\mathrm{ub}}(\langle C\rangle,\langle\varphi\rangle)=61.62
$$

With this kind of simplified criterion, the reinforced soil may be considered as an equivalent material with isotropic strength properties $(\langle C\rangle,\langle\varphi\rangle)$. As we have already highlighted previously, the assumption is in strong contradiction with the numerical assessment of the macroscopic strength domain.

As a result, the stability factor evaluation is overestimated by a factor 4 when adopting the simplified criterion. Such a result can be, at least partially, explained by the fact that, unlike for the exact macroscopic strength criterion, the strength of the reinforced soil under a pure shear solicitation remains unlimited with this simplified criterion.

\section{CONCLUDING REMARKS}

The present contribution concerns the evaluation of the macroscopic strength domain of a stone column reinforced soil. Using a numerical code, the obtained result represents a rigorous upper bound estimate of this domain. It has been highlighted that the direct use of this domain is impossible for a structural stability analysis. Hence, a numerical procedure has been used in order to approximate the so-obtained strength domain. The accuracy of this approximation method has been quantified.

This approximation is then used on an illustrative example. The case of an embankment resting upon a stone column reinforced soil is treated. As expected, the reinforcement technique provides a gain in terms of ultimate stability factor, comparatively to the non reinforced soil structure. However, this gain is less substantial than that predicted with a non rigorous 
simplified method, based on a rule of mixture formula.

The same method could be used for a yield design static approach. This approach would provide a lower bound estimate for the macroscopic strength domain (Gueguin et al. 2014a) and the approximation by a set of ellipsoids could be performed as well. Finally, a lower bound estimate of the ultimate stability factor would be obtained and $\mathrm{F}^{+}$could be framed between two rigorous bounds.

As it has been previously underlined, the strength of the stone column reinforced soil is limited to the cohesion of the native soil for a pure shear solicitation. This remark certainly has an influence on the stability analysis for a structure using this kind of reinforced soil.

An alternative soil reinforcement technique has been quite recently developed: the so-called cross trench reinforcement technique (Jeanty et al. 2013). The frictional reinforcing material is introduced in the form of a network of two perpendicular arrays of trenches, in much the same way as a honeycomb structure.

It could represent an interesting alternative to the columnar configuration, since it provides an infinite strength under pure shear macroscopic stresses. The improvement of the structural behaviour due to this configuration has already been highlighted in the case of a purely cohesive reinforcement material (Gueguin et al. 2014b) and could also be expected in the case of a frictional material.

\section{REFERENCES}

Bleyer, J. \& P. de Buhan (2013). Yield surface approximation for lower and upper bound yield design of $3 \mathrm{~d}$ composite frame structures. Computers \& Structures 129, 86-98.

Broms, B. (1982). Lime columns in theory and practice. In Proc. Int. Conf. of Soil Mechanics, pp. 149-165.

de Buhan, P. (1986). A fundamental approach to the yield design of reinforced soil structures (in french). Thèse d'Etat. Paris VI.

Gueguin, M., G. Hassen, J. Bleyer, \& P. de Buhan (2013). An optimization method for approximating the macroscopic strength criterion of stone column reinforced soils. In Proceedings of the 3rd International Symposium on Computational Geomechanics, pp. 484-494.

Gueguin, M., G. Hassen, \& P. de Buhan (2014a). Numerical assessment of the macroscopic strength criterion of reinforced soils, using semidefinite programming. International Journal for Numerical Methods in Engineering, Submitted.

Gueguin, M., G. Hassen, \& P. de Buhan (2014b). Ultimate bearing capacity of a foundation reinforced by columns or cross trenches under inclined loads: homogenization approach. International Journal for Numerical and Analytical Methods in Geomechanics, Accepted.

Hassen, G., M. Gueguin, \& P. de Buhan (2013). A homogenization approach for assessing the yield strength properties of stone column reinforced soils. European Journal of Mechanics-A/Solids 37, 266-280.

Jeanty, J. M., F. Mathieu, L. Benhamou, \& P. Berthelot (2013).
Importance et applications des inclusions de grande inertie. In Proceedings of the 18th International Conference on Soil Mechanics and Geotechnical Engineering, pp. 2505-2508.

Jellali, B., M. Bouassida, \& P. de Buhan (2007). A homogenization approach to estimate the ultimate bearing capacity of a stone column reinforced foundation. International Journal of Geotechnical Engineering 1(9), 61-69.

Jellali, B., M. Bouassida, \& P. de Buhan (2011). Stability analysis of an embankment resting upon a column-reinforced soil. International Journal for Numerical and Analytical Methods in Geomechanics 35(11), 1243-1256.

Makrodimopoulos, A. \& C. M. Martin (2007). Upper bound limit analysis using simplex strain elements and secondorder cone programming. International Journal for Numerical and Analytical Methods in Geomechanics 31(6), 835865.

Priebe, H. J. (1995). The design of vibro replacement. Ground Engineering 28(10), 31-37.

Suquet, P. (1987). Elements of homogenization for inelastic solid mechanics. In Homogenization Techniques for Composite Media, 278, pp. 193-278. 